\title{
OS AGUDÁS DE LAGOS: BRASIL, CUBA E MEMÓRIAS ATLÂNTICAS
}

CUNHA, Manuela Carneiro da. Negros, estrangeiros: os escravos libertos e sua volta à África. [2 $2^{\mathrm{a}}$ edição, revista e ampliada]. São Paulo: Companhia das Letras, 2012. 279 p.

OTERO, Solimar. Afro-Cuban Diasporas in the Atlantic World. Rochester: University of Rochester Press, 2010. 247 p.

$H_{\text {oje, as diferentes regiões da diás- }}$ pora africana são pensadas como partes de um todo historicamente interligado, inclusive por viajantes e marinheiros negros que circulavam entre os diversos portos durante o tempo da escravidão. Em grande medida, esse paradigma ganhou visibilidade através de Paul Gilroy, cujo influente livro O Atlântico Negro (1993), examinou a comunicação dinâmica entre intelectuais e artistas negros em diferentes partes do Atlântico anglófono. Contudo, nos estudos afro-brasileiros o tropo do viajante negro já era conhecido, desde Nina Rodrigues, que, no alvorecer do século XX, descreveu, num trecho comovente de Os africanos no Brasil, o embarque de um grupo de velhos africanos para Lagos após a Abolição. O tema das idas e vindas de libertos entre a Bahia e Lagos seria retomada nos anos 1940 pelo pesqui- sador norteamericano Lorenzo Turner. Na década seguinte Pierre Verger começou a aprofundar a questão com mais detalhe, apontando para o grande número de africanos que saíram do Brasil, expulsos ou de moto próprio, após a Revolta dos malês e documentando a existência, nos anos 1950, de uma identidade brasileira em várias cidades do Golfo do Benim, a qual persiste até hoje.

Nos anos a seguir, outros trabalhos acadêmicos vieram à luz, sendo o mais notável, sem dúvida, Negros, estrangeiros: os escravos libertos e sua volta à África, da antropóloga Manuela Carneiro da Cunha. Originalmente lançado em 1985, mas esgotado há anos, acaba de ganhar uma bela reedição pela Companhia das Letras. A preocupação central da autora é traçar os contornos da identidade fragmentada dos retornados, comparando suas experiências nos 
dois lados do Atlântico. Tratados como forasteiros no Brasil, também foram percebidos como estrangeiros - e se sentiram como tal - depois do retorno à África. No Brasil, eram subalternos, unidos entre si pela experiência da escravidão e da luta pela alforria e ascensão social, mas, uma vez na África a bagagem cultural adquirida no Brasil resultou ser uma ferramenta muito útil no contexto colonial africano.

A autora divide a obra em duas partes, na primeira analisa experiência do africano no Brasil, com ênfase na Bahia, e na segunda aborda o mundo dos retornados na África, com destaque para a cidade de Lagos, na atual Nigéria. $O$ primeiro capítulo examina a questão étnico-racial no Brasil escravista, discutindo as divisões e as solidariedades entre pardos, crioulos e as diversas nações africanas, as diferentes experiências de escravos no meio rural e na cidade, a alforria e os vários caminhos para consegui-la. No segundo capítulo, a autora explora um tema essencial para o seu argumento: a precariedade jurídica e social do africano liberto no Brasil. Os libertos aqui nascidos, embora estigmatizados pelo tempo vivido sob cativeiro, desfrutavam de certos direitos, como o de votar em eleições primárias, se candidatar para ser vereador ou entrar nas forças armadas, mas esses meios de inclusão política eram vedados aos africanos, que "não gozavam nem do status de brasileiro nem das garantias de estrangeiros protegidos por seu país de origem" (p. 101).

Em 1835, após a Revolta dos malês, o governo provincial da Bahia chegou a cogitar a deportação de todos os africanos libertos, mas, tendo expulsado alguns considerados suspeitos de conspirar, acabou se limitando à implementação de restrições para dificultar a vida dos que ficaram. Essa medida foi complementada pela aplicação mais sistemática de uma lei imperial existente desde 1831, que proibia o desembarque de africanos libertos em qualquer porto nacional. Ou seja, a lei de 1835 procurou incentivar o africano a sair do país depois de liberto, enquanto a de 1831 impossibilitava sua volta. Para Cunha, esse momento marcou o início de um agravamento progressivo da situação dos africanos libertos no Brasil, que se acelerou com o fim do tráfico e, paradoxalmente, não melhorou com o movimento abolicionista. No imaginário da elite brasileira, o negro, especialmente o africano, era concebido como sinônimo de escravo, incompatível com os avanços sociais representados pela transição ao trabalho livre, enquanto a importação de trabalhadores europeus era vista como um símbolo de modernização e progresso. Esse crescente clima de marginalização do negro, mais intenso para o africano, teria sido o pano 
de fundo do movimento de retorno à África.

Na segunda parte do livro, Cunha desloca sua atenção para a cidade de Lagos. Quando foi tomada pelos britânicos em 1851, Lagos era o maior porto de embarque de escravos na África ocidental. A intervenção, um ano após a lei Eusébio Queiroz, foi justificada pelos ingleses como mais um passo no combate para acabar com o tráfico negreiro. Em 1861, a cidade se tornou oficialmente um protetorado da Coroa Inglesa. Para o africano liberto que queria se reinstalar no continente natal, a cidade passou a representar um porto seguro: era o único lugar na região que oferecia alguma proteção contra o risco real de reescravização. Inicialmente, o obá de Lagos cobrava um imposto alto de desembarque aos retornados, mas em 1857, com o fim da cobrança, a cidade se tornou cada vez mais atraente para libertos chegando das Américas.

Os retornados do Brasil ficaram conhecidos como agudás, provavelmente uma corruptela de Ajudá, o antigo nome dado pelos portugueses para Uidá, onde a primeira colônia de libertos do Brasil surgiu. Outro grupo importante era formado pelos saros, ou seja, africanos livres que tinham vivido em Serra Leoa após serem resgatados de navios negreiros capturados no alto mar pelos cruzeiros ingleses. Na nova colônia de La- gos, saros e agudás, conhecidos coletivamente como "repatriados", passaram a constituir elites em relação à população nativa, ajudados pela familiaridade com os costumes e idiomas europeus.

Os saros, que falavam inglês e seguiam o protestantismo do colonizador, tinham certas vantagens, mas, na disputa pelas oportunidades de emprego da emergente economia local, os brasileiros tinham habilidades mais rentáveis, consequência de seus anos de trabalho no Brasil. Os ofícios dos homens - pedreiros, mestres de obras, marceneiros, sapateiros, ferreiros e diversos outros artesãos -, bem como os das mulheres - lavadeiras, costureiras e quituteiras - eram valorizados pelos novos governantes. Outros agudás se tornaram negociantes de exportação, tratando principalmente com o Brasil, para onde enviavam produtos como noz-de-cola, pano da costa, sabão preto e azeite de dendê. Este último, com a extinção do tráfico, se tornou o produto mais exportado da região, em demanda no mercado europeu como combustível e lubrificante industrial, bem como na fabricação de velas de estearina. Com o descobrimento de petróleo, entretanto, o preço de azeite de dendê caiu. Mas a partir dos anos 1870 surgiu uma demanda por outro produto do dendezeiro: o óleo extraído da amêndoa do caroço, utilizado na fabricação de sabão e de margarina. 
Assim como no tempo do tráfico de escravos, no comércio dos produtos do dendezeiro, Lagos era apenas o porto de desembarque de mercadoria que chegava do interior, por intermediação de atravessadores. Para o retornado que procurava entrar nesse lucrativo mercado, pertencer a um dos subgrupos iorubás estabelecidos nos locais de produção possibilitava aproveitar contatos preexistentes na criação de uma rede de negócios. Esse quadro de comércio internacional facilitava o movimento de libertos entre Lagos e Brasil, mas com o tempo a economia da colônia passou a ser cada vez mais atrelada ao comércio com a metrópole inglesa. Em decorrência disso, o número de navios que faziam o percurso entre o Golfo do Benim e o Brasil foi-se reduzindo. Ao longo do tempo, isto prejudicou a manutenção dos laços entre os agudás e os afrodescendentes no Brasil.

Na sociedade lagosiana, os agudás se organizaram em grandes redes de clientelismo, também criando sociedades de ajuda mútua que assemelhavam, nesse sentido, o papel desempenhado pelas irmandades católicas no Brasil. Através desses mecanismos, os recém-chegados a Lagos se articularam com os retornados já estabelecidos. A coesão da comunidade girava em torno da memória compartilhada do Brasil, fato evidente na perpetuação de festas populares brasileiras como a do Senhor do Bonfim e o bumba-meu-boi. Com o passar do tempo, essa primeira manifestação sofreu uma mudança de gênero, sendo reconfigurada como a "Senhora" do Bonfim. Apesar de pequenas mudanças como esta, a persistência de costumes brasileiros ao longo das décadas, assim como o uso de sobrenomes aqui adotados e da língua portuguesa eram a cola que ligava os agudás, simultaneamente marcandoos como estrangeiros em relação ao resto da sociedade de Lagos.

Não obstante essa coesão, a comunidade agudá também era heterogênea. Os falantes de iorubá eram majoritários, mas também havia haussás, nupes (chamados tapas na Bahia), ibos etc. Além do mais, os próprios iorubás eram uma aglutinação de várias subetnias: oiós, ijebus, ijexás etc., com os egbás, vítimas da última fase do tráfico, sendo os mais numerosos. Um dos subgrupos agudás, inclusive, não compartilhava as heranças culturais brasileiras do resto, pois tinha sido escravizado em Cuba. Apesar dessa grande diferença, os agudás cubanos foram absorvidos, em grande medida, pela comunidade "brasileira", devido às semelhanças linguísticas entre o português e o espanhol e à religião comum, o catolicismo.

O papel aglutinador do catolicismo na comunidade agudá é o tema do quarto e último capítulo. Para $\mathrm{Cu}$ nha, a dimensão religiosa constitui o mais importante sinal diacrítico da 
identidade agudá, em oposição ao protestantismo inglês adotado pelos saros de Serra Leoa. O capítulo começa traçando os primórdios da presença católica na cidade de Lagos. Um grupo missionário de Lyons, a Societé des Missions Africaines (doravante SMA), fundou a primeira missão católica da região em Uidá, em 1861, mas em Lagos o cenário missionário era constituído apenas por protestantes, sem sequer um padre católico. Havia um religioso leigo, um africano liberto que realizava ritos católicos extraoficialmente, mas com a presença da SMA no Daomé os agudás de Lagos reivindicaram sua própria missão, pedido que foi atendido em 1868.

Em 1879, com recursos financeiros doados por agudás abastados, deu-se início às obras de uma igreja - que substituiria uma estrutura mais rudimentar coberta de palha -, sob a direção do agudá Lázaro Borges da Silva. Inaugurada em 1881 e batizada oficialmente como Holy Cross Church (Igreja da Santa Cruz), a igreja foi sempre chamada de "catedral" pelos agudás, apesar de Lagos estar ainda longe de tornar-se uma diocese. Admirada pelos ingleses, a igreja se tornou um símbolo da importante contribuição agudá à arquitetura local, evidente também em muitas construções privadas, como a residência do comerciante João Esan da Rocha, popularmente conhecida como a Casa
d'Água, que deu título ao romance de Antônio Olinto.

Apesar de se identificarem intensamente com o catolicismo, os agudás resistiram a determinados preceitos, como a monogamia e a proibição ao culto a "falsos ídolos". Em relação á primeira questão, na impossibilidade de prevalecer, os missionários faziam vistas grossas, mas foram mais insistentes em relação à segunda, sem, porém, muito sucesso. Recusando-se a abandonar seus "fetiches", os fieis argumentavam que "é preciso ter fetiches como se tem amigos. Quanto mais os temos, melhor, se um não nos ajudar, o outro o fará" (p. 196). Por outro lado, eram entusiásticos em relação a outra questão cara aos missionários, a criação de uma escola, desde que a língua das aulas fosse $o$ português. À medida que a presença inglesa na região foi se firmando, entretanto, a língua do colonizador se tornou cada vez mais importante e acabou sendo adotada na escola católica nos anos 1880 . O uso do português no cotidiano da comunidade agudá, porém, perdurou até pelo menos os anos 1920. Mesmo nos anos 1970 , quando a autora realizava seu trabalho de campo, ainda se encontravam pessoas que se lembravam de provérbios, canções e expressões idiomáticas levadas do Brasil.

Negros, estrangeiros é um trabalho interdisciplinar que utiliza dados históricos e informações etnográficas 
para desenvolver um olhar teórico sobre diásporas e a construção de identidades híbridas transnacionais. Nesse sentido, o livro antecipou a importância do viajante negro para a diáspora africana que entraria em moda na década seguinte, também prevendo ideias sobre a fragmentação do sujeito e a natureza relacional da identidade que se tornariam centrais em discussões pós-modernistas. Da perspectiva historiográfica, são os capítulos sobre Lagos que mais chamam a atenção. Fruto de minuciosa pesquisa documental em diversos arquivos no Brasil e no exterior, essa parte do livro permanece uma referência ímpar. A nova edição brinda o leitor com raras imagens históricas do acervo da SMA e fotos da arquitetura agudá da autoria de Pierre Verger tiradas em meados do século XX. Outra novidade é a inclusão de diversas fotos oitocentistas de africanos no Brasil. Sentimos um pouco a decisão de retirar um apêndice que fazia parte da primeira edição, com valiosas estimativas do fluxo de libertos que tomaram rumo à África e do crescimento da população agudá. Mas este pequeno detalhe em nada diminui a imensa satisfação de ver este clássico dos estudos afro-brasileiros de volta às livrarias, sobretudo neste momento nos estudos da diáspora africana, quando a importância do viajante negro no mundo atlântico está sendo cada vez mais reconhecida.
Nesse sentido, também é oportuna a publicação do livro Afro-Cuban Diasporas in the Atlantic World, uma adaptação da tese de doutorado da folclorista Solimar Otero, professora da Louisiana State University, sobre os agudás oriundos de Cuba. Com apenas um trabalho anterior sobre o assunto, os retornados cubanos permaneceram muito tempo na sombra de estudos sobre seus pares brasileiros. ${ }^{1}$ Como Cunha, Otero cruza trabalho de campo etnográfico com uma perspectiva histórica. Contudo, enquanto em Negros, estrangeiros a análise dos motivos para as travessias de retorno aponta para a precariedade política e econômica do africano liberto na sociedade escravista, para Otero as idas a Lagos representam o retorno à pátria. E enquanto Cunha ressalta o papel do catolicismo em consolidar uma identidade agudá fundamentada na diferença, Otero se detém sobre a importância da religiosidade tradicional em reintegrar os retornados na sociedade do seu continente natal.

No primeiro capítulo, Otero apresenta um panorama do período do tráfico clandestino de escravos para Cuba, que terminou apenas em meados dos anos 1860. Como no Brasil, em Cuba havia uma população considerável de africanos livres, conse-

\footnotetext{
Rodolfo Sarracino, Los que volvieron a África, Havana: Editorial de Ciencias Sociales, 1988.
} 
quência das apreensões de navios negreiros pelos ingleses. Otero cita o caso de Nicolás Lucumí, um egbá evangelizado ainda em Abeokuta e capturado durante o ataque daomeano àquela cidade em 1855 . Nicolás teve a perspicácia de enviar uma carta a sua família, que acionou os missionários de Abeokuta, com o resultado de que o influente missionário saro, Samuel Crowther (futuro primeiro bispo anglicano na África), bancaria sua passagem de volta. Mas trata-se de um caso excepcional. Assim como no Brasil, a grande maioria dos africanos livres de Cuba permaneceu a serviço do governo ou de particulares por muitos anos antes de vivenciar a plena liberdade.

Fosse africano livre ou liberto, o retornado de Cuba geralmente pagava ele mesmo sua passagem com capital acumulado ao longo de anos de trabalho ou, às vezes, com lucros provenientes de investimentos em imóveis ou em escravos. Havia também os que tinham a sorte de acertar na loteria, porém não era muito comum. Devido à proximidade de Cuba com as colônias britânicas no Caribe, a viagem para Lagos frequentemente acontecia em navios ingleses com escalas em Londres. Como no Brasil, o movimento de retorno se intensificou depois de revoltas escravas. Em 1844, após a conspiração denominada La Escalera, teriam sido deportados para a África cerca de qua- trocentos africanos libertos. No mesmo ano, deixou a ilha voluntariamente um grupo de setenta a oitenta libertos a bordo do bergantim San Antonio, segundo Otero, rumo a Lagos.

Lagos ocupa um lugar central na análise da autora, não apenas por ser o porto de embarque para o cativo e de desembarque para o retornado, mas porque, para a autora, a cidade teria sido o lugar de nascimento da população lucumí, como os iorubás eram conhecidos em Cuba. Seguindo as ideias de Lorand Matory sobre o papel de Lagos na construção de identidades iorubás diaspóricas, ${ }^{2}$ Otero amplia bastante o horizonte temporal, sustentando que "uma diáspora lagosiana estava sendo formada entre as classes populares da Havana urbana entre 1825 e 1860" (p. 43). Mas essa tese se apoia numa única fonte, de 1854 , relativa a um pequeno grupo de 23 libertos que, após mais de vinte anos em Cuba, voltou à África. Nos depoimentos, a metade deste grupo reivindicou ser "natural" de Lagos. Enquanto essa informação é adotada pela autora de forma acrítica, paira um silêncio total sobre a

\footnotetext{
J. Lorand Matory, Black Atlantic Religion: Tradition, Transnationalism and Matriarchy in the Afro-Brazilian Candomblé, Princeton: Princeton University Press, 2005, cap. 1; idem, "The English Professors of Brazil: on the Diasporic Roots of the Yoruba Nation", Comparative Studies in Society and History, v. 41 (1999), pp. 72-103.
} 
vasta literatura historiográfica que demonstra que a maioria dos iorubás embarcados para Cuba nesse período veio das regiões do interior conturbadas por guerras ao longo da primeira metade do Oitocentos. Otero sequer comenta a evidência contrária apresentada no seu próprio texto, como a do retornado Nicolás Lucumí, que, como vimos acima, era de Egba. ${ }^{3}$

No segundo capítulo, a análise da autora se desloca para o contexto social de Lagos. O ponto de partida é um questionamento do significado, na cultura iorubá, dos conceitos de diáspora e de dispersão. Segundo ela, a importância desses conceitos antecede em muito o tráfico de escravos, evidenciado pelo próprio mito de origem dos iorubás, em que o pai ancestral, Oduduwa, manda seus dezesseis filhos

saírem de Ile-Ife para diferentes regiões para fundar os reinos iorubás, assim alimentando uma sensibilidade diaspórica singular na criação de cultura e de história (p. 39).

3 Entre outros, ver Toyin Falola e Matt Childs (orgs.), The Yoruba Diaspora in the Atlantic World, Bloomington: Indiana University Press, 2004; e Jesús Guanché, Africanía y etnicidad en Cuba: los componentes étnicos africanos y sus múltiples denominaciones, Havana: Editorial de Ciencias Sociales, 2009. Neste último, entre 112 variações do etnônimo lucumí encontradas na literatura, como lucumi efon, lucumí ijesá, lucumí oyó etc, não consta nenhuma referência a Ekó, o nome nativo de Lagos.
Essa sensibilidade ter-se-ia enraizado no pensamento cultural dos iorubás. A cidade de Lagos, ou Ekó como era então conhecida, foi fundada a partir dessa diáspora primordial e agregava características cosmopolitas impostas por sua localização geográfica, na fronteira com o reino do Benin, a nordeste, e ao norte, com os territórios de Egbado e Awori. No século XIX, quando começaram as guerras civis no interior dos territórios iorubás, Lagos absorvia algumas das pessoas deslocadas por esses conflitos. Nesse período também, com sua ascensão econômica como porto do comércio negreiro, a cidade passou a ser o ponto de dispersão para a maioria dos iorubás vendidos para as Américas. O caráter cosmopolita da cidade teria incentivado uma flexibilidade em relação às práticas culturais de outras etnias, o que faria os cativos exportados receptivos a novas práticas e costumes, entre elas, preceitos religiosos. A tendência de acrescentar práticas religiosas, ao invés de vê-las como mutuamente incompatíveis, seria essencial para a adaptação à vida no outro lado do mar e novamente durante o processo de readaptação depois do retorno.

$\mathrm{Na}$ organização social dessa cidade multiétnica, que agrupava migrantes do interior e do outro lado do mar, o babá isale (cargo indicado pelo chefe de uma cidade para representálo oficialmente em outro lugar) assu- 
miu importância especial, atuando como chefe dos seus conterrâneos, que estabeleciam residência na vizinhança da sua casa. Assim nasceram e cresceram bairros étnicos dentro do perímetro urbano de Lagos. Os agudás e os saros também tinham - e têm - seus chefes. Cada segmento da sociedade iorubá é organizado de forma hierárquica: comerciantes se organizam de acordo com o tipo de mercadoria (vendedores de tecidos, de farinha etc.), famílias designam seus chefes, grupos religiosos também o fazem etc. Esta análise, um dos pontos mais fortes do livro, é baseada em entrevistas etnográficas com um filho do chefe dos saros, Prince Olusí, que através de sua família participa ativamente da governança tradicional da ilha de Lagos.

A partir desses dados, Otero sugere que as formas de organização social dos iorubás influenciaram a criação de redes de sociabilidade entre os lucumís em Cuba, a exemplo dos cabildos, e que a mesma tendência a transportar e reconfigurar estruturas sociais já conhecidas provavelmente se reproduzia em outras partes da diáspora. Diante da tremenda importância da hierarquia até hoje nos terreiros de candomblé, e historicamente dos sistemas de organização de instituições como os cantos de trabalho e as juntas de alforria no Brasil, esse argumento é bem plausível.

No terceiro e quarto capítulos, também de caráter etnográfico, o enfoque se desloca para a religiosidade agudá. Volta à cena o príncipe saro Olosí, com vários depoimentos fascinantes, inclusive sobre a participação paralela em diferentes cultos. Aqui também ouvimos a voz de um agudá brasileiro, Paul Lola Bamgbosé Martins, que detém um posto importante no culto aos ancestrais, egungun (o babá egun do Brasil). Seus depoimentos são de interesse especial para o público brasileiro, por ser ele bisneto do retornado Rodolfo Manoel Martins de Andrade, ou Bamboxê Obitikô, que também deixou descendentes na Bahia, onde exerceu um papel influente nos primeiros tempos do Terreiro da Casa Branca. Nesta parte do livro, também ouvimos as vozes de duas netas de Hilario Campos, um babalaô nascido em Cuba que publicamente se apresentava sempre como católico.

Essas duas irmãs são as únicas descendentes de retornados cubanos que aparecem no livro, o que enfraquece a etnografia, em termos empíricos. A análise de como "nostalgia, memória e o papel da imaginação alimentam o senso de pertencimento" (p. 5), em vez de dizer respeito às "diásporas afro-cubanas no mundo atlântico" do título, é reduzida às parcas memórias de duas idosas sobre um avô que faleceu quando eram ainda crianças. O papel da imaginação na construção das memórias por elas 
compartilhadas permanece elusivo. Não há evidência de como essas memórias se entrelaçam com - ou se afastam de - acontecimentos na micro-história da trajetória familiar. São escassos os dados biográficos apresentados sobre Hilario Campos (1878-1941): nasceu em Matanzas, falava mais espanhol do que iorubá e, junto com duas irmãs, migrou a Lagos como homem jovem (p. 101), onde constituiu família e, em momento indeterminado, fundou um centro cultural para retornados de Cuba, o Afro-Cuban Lodge (p.73).

Otero retrata Hilario Campos como um homem de grande prestígio na comunidade agudá, "fundador de um bairro inteiro" (p. 86), que teria dado nome a uma praça importante no centro do bairro agudá, o Campos Square (p. 88). Porém, na verdade, a praça foi batizada quando Hilario Campos ainda era uma criança em Cuba, em homenagem a um retornado brasileiro com o mesmo sobrenome. Romão Campos, que morava na cidade desde pelo menos os anos 1860 , tinha uma loja de tecidos e ferragens na praça, que em 1885 já levava seu nome. ${ }^{4}$ Essas informações - a maio-

\footnotetext{
4 Lagos Land Registry, "Plan of the Town of Lagos, 1885", apud Jean Herskovits Kopytoff, A Preface to Modern Nigeria: the "Sierra Leonians" in Yoruba, 1830-1890, Madison: University of Wisconsin Press, 1965, pp. 91-3; A. B. Laotan, The Torch Bearers, or, Old Brazilian Colony in Lagos, Lagos: Ife-Olu Printing Works, 1943, p. 12;
}

ria presentes em textos citados na própria bibliografia da autora - lançam dúvida em relação a suas interpretações sobre a influência de Hilario Campos na sociedade lagosiana.

Tradições orais são fontes preciosas, mas além de proporcionar fatos valiosos, no sentido literal, elas também são narrativas metafóricas, repletas de omissões e inserções seletivas. O silêncio dos descendentes de Hilario Campos sobre a família brasileira com o mesmo sobrenome se oferece como um ponto de partida para reflexões férteis sobre as relações entre as duas famílias e suas possíveis alianças e concorrências, bem como as dinâmicas entre agudás brasileiros e cubanos de modo mais geral, nada disso, infelizmente explorado aqui.

Negros, estrangeiros e AfroCuban Diasporas in the Atlantic World são livros que, de certa forma, se espelham, não apenas por se tratarem de agudás, mas porque ambos procuram compreender a construção dessa identidade diaspórica. Porém,

Lagos Standard, 15/1/1886, apud Verger, Fluxo e refluxo do tráfico de escravos entre o Golfo do Benin e a Bahia de Todos os Santos, $4^{a}$ ed., Salvador: Corrupio, 2002, p. 660. Romão Campos morava em Lagos desde pelo menos os anos 1860 , recebendo um terreno do obá em 1868: Lagos Land Registry, Dosomu Crown Grants, vol. 3, 1/mar/1868-18/mar/1869. Agradeço a Kristin Mann por disponibilizar esta informação. 
enquanto Cunha a enxerga através da lente do eterno forasteiro, Otero dá destaque ao sentimento de pertencimento transatlântico. Outra diferença reside na base empírica das pesquisas. Se Cunha surpreende o leitor com a fartura, Otero promete mais do que cumpre. De acordo com esta úl- tima autora, até a publicação do seu livro, a história dos agudás era "praticamente desconhecida" (p. 10). O desconhecimento, entretanto, é da academia anglófona. $\mathrm{Na}$ esperança de que isso seja revertido, ficamos no aguardo de uma tradução para o inglês de Negros, estrangeiros.

Lisa Earl Castillo lisa.earl.castillo@gmail.com Bolsista Fapesp de Pós-Doutorado Universidade Estadual de Campinas-

UNICAMP 
